\title{
Uso de Brassica Juncea (L.) Czern, Helianthus Annus L. e mimosa bimucronata (dc) o. Kuntze na fitorremediação de solos contaminados com chumbo e níquel
}

A fitorremediação é uma técnica de descontaminação de solos em que se utiliza o potencial de espécies vegetais para extrair metais e outros contaminantes do ambiente. Neste trabalho foram utilizadas as espécies Brassica juncea (L.) Czern (Mostarda), Helianthus annus L. (Girassol) e Mimosa bimucronata (DC.) O. Kuntze (Maricá) para fitoextrair chumbo e níquel de solos. Para a realização do procedimento, foi feito o acompanhamento ao longo de 11 semanas de dois experimentos simultâneos em que o solo utilizado foi Latossolo Vermelho coletado dentro dos limites da Universidade Tecnológica federal do Paraná. No experimento 1 , utilizaram-se $2 \mathrm{~kg}$ (massa seca) em potes de polipropileno contaminados com acetato de chumbo e sulfato de níquel em concentrações de $0,5,1,0,2,0$ e $5,0 \mathrm{~g} / \mathrm{kg}$ de chumbo e níquel, para identificar o potencial fitorremediador de Brassica juncea (L.) Czern e Helianthus annus L. Para o segundo experimento, foi utilizado $1 \mathrm{~kg}$ (massa seca) de solo contaminado com acetato de chumbo em concentrações de 0,25, 0,5 e 1,0 g/kg para verificar se a Mimosa bimucronata (DC.) e O. Kuntze possuem potencial fitorremediador.

Palavras-chave: Biorremediação; Fitorremediação; Fitoextração; Metal pesado; Solo contaminado.

\section{Use of Brassica Juncea (L.) Czern, Helianthus Annus L. and mimosa bimucronata (dc) o. Kuntze in the phytorremediation of lead contaminated with nickel}

\begin{abstract}
Phytoremediation is a soil decontamination technique in which the potential of plant species is used to extract metals and other contaminants from the environment. Brassica juncea (L.) Czern (Mustard), Helianthus annus L. (Sunflower) and Mimosa bimucronata (DC.) O. Kuntze (Maricá) species were used to extract lead and nickel from soils. For the accomplishment of the procedure, it was made the follow-up throughout 11 weeks of two simultaneous experiments in which the soil used was Red Latosol collected within the limits of the Federal Technological University of Paraná. In experiment 1, 2 kg (dry mass) was used in polypropylene pots contaminated with lead acetate and nickel sulfate at concentrations of $0.5,1.0,2.0$ and $5.0 \mathrm{~g} / \mathrm{kg}$ of lead and nickel, to identify the phytoremediation potential of Brassica juncea (L.) Czern and Helianthus annus L. For the second experiment, $1 \mathrm{~kg}$ (dry mass) of lead acetate contaminated soil was used at concentrations of $0.25,0.5$ and $1.0 \mathrm{~g} / \mathrm{kg}$ to verify that Mimosa bimucronata (DC.) and O. Kuntze have phytoremediation potential.
\end{abstract}

Keywords: Bioremediation; Phytoremediation; Phytoextraction; Heavy metal; Contaminated soil.

Topic: Desenvolvimento, Sustentabilidade e Meio Ambiente

Reviewed anonymously in the process of blind peer.
Received: 04/12/2020 Approved: 21/12/2020
Maryiá Yuki Tokuho

Universidade Tecnológica Federal do Paraná, Brasil http://lattes.cnpq.br/2053915963928802

http://orcid.org/0000-0001-5816-9966

mariya_tokuho@hotmail.com

Nelson Consolin Filho (iD

Universidade Tecnológica Federal do Paraná, Brasil http://lattes.cnpq.br/5820606948533146

http://orcid.org/0000-0002-4847-0701

consolin@utfpr.edu.br

Flávia Vieira da Silva Medeiros (ic

Universidade Tecnológica Federal do Paraná, Brasil

http://lattes.cnpq.br/8298141172237555

http://orcid.org/0000-0001-6490-8876

flaviav@utfpr.edu.br
José Hilton Bernardino de Araújo

Universidade Tecnológica Federal do Paraná, Brasil

http://lattes.cnpq.br/4560874870987991

http://orcid.org/0000-0001-9743-7855

jaraujo@utfpr.edu.br
Referencing this:

TOKUHO, M. Y.; CONSOLIN FILHO, N.; MEDEIROS, F. V. S.; ARAÚJO, J. H. B.. Uso de Brassica Juncea (L.) Czern, Helianthus Annus L. e mimosa bimucronata (dc) o. Kuntze na fitorremediação de solos contaminados com chumbo e níquel. Revista Ibero Americana de Ciências Ambientais, v.11, n.7, p.463-473, 2020. DOI:

http://doi.org/10.6008/CBPC2179-6858.2020.007.0037 


\section{INTRODUÇÃO}

A contaminação dos solos por elementos químicos é algo de grande preocupação nos dias de hoje. Guaracho et al. (2004) explica que o solo poluído se torna uma ameaça ao meio ambiente por apresentar substâncias tóxicas, entre estas substâncias podemos citar os metais pesados.

Em 2015 e 2019 o Brasil presenciou dois dos maiores desastres ambientais, o rompimento das barragens de mineração dos municípios de Mariana e Brumadinho, ambos no estado de Minas Gerais. No primeiro evento, foram transportados cerca de 50 milhões de $\mathrm{m}^{3}$ de resíduos de mineração na bacia do Rio Doce (DINIZ et al., 2018; ZHOURI et al., 2017). Já no segundo evento, 13 milhões de $\mathrm{m}^{3}$ de rejeitos da mineração foram lançados no meio ambiente sendo que a lama tóxica atingiu o Rio Paraopeba numa extensão aproximada de 250 km (FREITAS et al., 2019). Apesar da predominância de minérios de ferro, a lama dos desastres contém concentrações de variados metais, inclusive metais pesados como níquel, chumbo, cádmio e manganês (RIBEIRO et al., 2019). Esses acontecimentos evidenciam a necessidade de encontrar maneiras alternativas para depurar solos contaminados com metais pesados uma vez que é importante considerar que os metais, além de causar danos ao meio ambiente, também oferecem sérios riscos à saúde humana (GUARACHO et al., 2004).

A descontaminação de solos poluídos com metais pesados continua a ser um dos problemas mais difíceis de serem contornados (U.S. Army Toxic and Hazardous Materials Agency (1987, citado por BAKER et al., 1994)). A seleção do método de remediação de solo e sedimento mais apropriado depende das características do local, concentração, tipo de poluente a ser removido e o uso final do meio contaminado (MULLIGAN et al., 2001).

As técnicas de remediação são variáveis, muitas destas tecnologias já são amplamente difundidas e utilizadas na remediação de solos, sedimentos, águas subterrâneas e superficiais, atmosfera e resíduos contaminados. Novas tecnologias estão sendo investigadas e entre estas, destaca-se a fitorremediação, a qual baseia-se na utilização de plantas como ferramenta principal. A técnica é complexa, por compreender um sistema vegetal dependente de vários fatores como por exemplo, adaptabilidade às condições edafoclimáticas locais, espécies de plantas adaptadas e a própria natureza e nível de contaminação da área (MONTEIRO, 2005).

A industrialização e a urbanização têm exposto animais e vegetais a elementos químicos potencialmente tóxicos. Entre estes, os metais pesados representam os maiores contaminantes industriais dos ecossistemas (CRUVINEL, 2009).

Entre os metais pesados existentes, a escolha para o estudo do chumbo como contaminante deu-se, pois segundo o Ministério da Saúde (2019) é uma substância capaz de persistir no solo e no fundo de rios durante várias décadas. Como consequência disso, há acumulação de chumbo ao longo das cadeias alimentares: os animais do topo da cadeia, entre eles o homem, acumulam altos teores de chumbo à medida que se alimentam de seres contaminados, podendo desenvolver problemas de saúde. Já o níquel é um metal pesado potencialmente tóxico que afeta vários órgãos dos sistemas vivos, além disso, as toxicidades do 
Uso de Brassica Juncea (L.) Czern, Helianthus Annus L. e mimosa bimucronata (dc) o. Kuntze na fitorremediação de solos contaminados com

níquel se manifestam com base na maneira de exposição, dose e duração (DAS et al., 2018).

Além dos riscos gerais para a saúde humana, o chumbo foi encontrado em concentrações acima do aceitável na lama proveniente do desastre de Brumadinho e o níquel, além de estar presente nos resíduos de Brumadinho, foi responsável pela intoxicação de pessoas em um município atingido pelo incidente de Mariana (FABRO, 2019; MOTA, 2018). Esses fatores demonstram a importância de se identificar maneiras de depurar o chumbo e níquel dos solos.

A descontaminação de uma área pode ser realizada por diversos métodos como a escavação do solo, uso de microrganismos, extração "in situ", vitrificação, entre outras, porém algumas dessas técnicas requerem muito tempo de execução, efeito visual e demanda de altos custos para efetivação do processo (ESTRELA et al., 2018).

O uso da fitorremediação é uma alternativa para a descontaminação de solos, Silva (2016) diz que esse método apresenta vantagens devido à sua natureza permanente, combinada a baixos custos de manutenção, proteção contra a erosão eólica e hídrica e maior estruturação dos solos.

Fitorremediação (em inglês phytoremediation em que 'phyto' significa planta e 'remediation' significa remediação) é um termo genérico para o grupo de tecnologias que utilizam plantas para remediar solos, lamas, sedimentos e água contaminada com contaminantes orgânicos e inorgânicos, pode ser definida como "o uso eficiente de plantas para remover, desintoxicar ou imobilizar contaminantes ambientais em uma matriz de crescimento (solo, água ou sedimentos) através de processos naturais biológicos, químicos ou físicos das plantas" (UNEP, 2018).

Como qualquer outro processo de remediação, o uso de plantas destina-se à redução dos teores de contaminantes a níveis seguros e compatíveis com a proteção à saúde humana, ou a impedir/dificultar a disseminação de substâncias nocivas ao ambiente (ANDRADE et al., 2007).

Greipsson (2011) salienta que é uma alternativa aos procedimentos de engenharia que geralmente são mais destrutivos para o solo, no entanto limita-se à zona das raízes das plantas. Além disso, esta tecnologia tem aplicação limitada, em que as concentrações de contaminantes são tóxicas para as plantas. As tecnologias de fitorremediação estão disponíveis para vários ambientes e tipos de contaminantes.

Ainda segundo o autor supracitado, a fitoextração usa a capacidade das plantas de acumular contaminantes acima do solo, na biomassa colhida (Figura 1). Este processo envolve repetidas colheitas de biomassa a fim de diminuir a concentração de contaminantes no solo. Fitoextração é também um processo contínuo (utilizando plantas hiperacumuladoras de metal ou plantas de rápido crescimento) ou um processo induzido (usando produtos químicos para aumentar a biodisponibilidade de metais no solo). A fitoextração contínua baseia-se na habilidade de certas plantas de acumularem gradualmente contaminantes (principalmente metais) em sua biomassa.

Neste estudo foram utilizadas sementes de Mostarda (Brassica juncea (L.) Czern), Girassol (Helianthus annuus L.) e Maricá (Mimosa bimucronata (DC.) O. Kuntze), para a fitorremediação de níquel e chumbo de amostras de solos contaminados. A escolha de Mostarda e Girassol deu-se por elas serem 
consideradas plantas hiperacumuladoras, ou seja, altamente especializadas em acumular ou tolerar concentrações elevadas de metais (RASKIN et al., 1994, citado por MARTINEZ et al., 2013). Já o Maricá foi escolhido por ser uma espécie que consegue naturalmente crescer em condições adversas. A ampla variedade e complexidade dos efluentes têxteis, aliadas a determinações da legislação que exigem tratamentos eficientes, têm levado à criação de novas tecnologias que buscam o tratamento melhor e mais adequado, ponderando despesas, tempo e eficiência. A coagulação e a floculação são técnicas muito utilizadas neste caso. Essa operação é considerada como um pré-tratamento que tem como objetivo o condicionamento do despejo para o tratamento subsequente (VAZ, 2009).

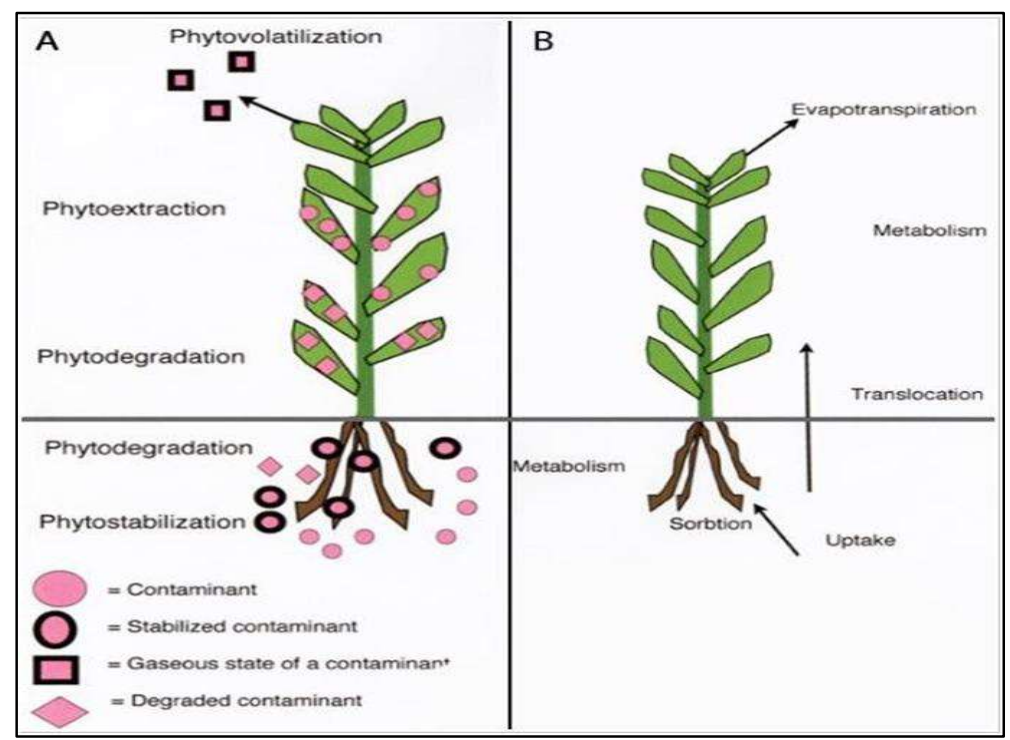

Figura 1: A) Modelo esquemático de diferentes tecnologias de fitorremediação envolvendo remoção e contenção de contaminantes; (B) Processos fisiológicos que ocorrem em plantas durante a fitorremediação (C) 2011 Nature Education. Todos os direitos reservados).

\section{MATERIAIS E MÉTODOS}

A metodologia foi fundamentada com base nos parâmetros estabelecidos pela USEPA 3050B que institui o Método de Digestão Ácida de Sedimentos, Lodos e Solos. Esta análise é utilizada para quantificar metais em solos e serve como alternativa para determinar o potencial fitorremediador de plantas uma vez que estas extraem os metais do solo, acumulando-os em seu tecido vegetal. A escolha para o procedimento de digestão de solos ao contrário da digestão do tecido vegetal foi utilizada, pois além da metodologia USEPA 3050B ser aceita pela Resolução CONAMA no 420 de 28 de dezembro de 2009 como procedimento padrão para extração de substâncias inorgânicas (exceto o mercúrio) de solos, buscou-se outra forma de procedimento para identificar a fitoextração de metais do solo.

\section{Local de estudo}

O estudo foi realizado nas dependências da Universidade Tecnológica Federal do Paraná (campus Campo Mourão), desta forma, o solo utilizado para a amostragem foi coletado no local. O solo da região é caracterizado como Latossolo Vermelho que apresenta cores vermelho acentuado devido aos teores mais altos e à natureza dos óxidos de ferro presentes, ocorrem predominantemente em áreas de relevo plano e 
Uso de Brassica Juncea (L.) Czern, Helianthus Annus L. e mimosa bimucronata (dc) o. Kuntze na fitorremediação de solos contaminados com

suave ondulado, são profundos e porosos ou muito porosos, em condições naturais apresentam baixos níveis de fósforo (AGEITEC, 2019).

\section{Preparo das amostras}

Foi retirada uma porção de $10 \mathrm{~g}$ do solo e colocado para secar em estufa com circulação de ar devidamente calibrada (Cienlab) para mensurar a porcentagem de umidade do solo utilizando a metodologia adaptada de Umidade Atual da Embrapa (1997), este procedimento foi necessário para que a quantidade de solo utilizado em cada amostra correspondesse à sua quantidade de solo seco, o que evita erros estequiométricos.

Foram feitos dois experimentos simultâneos sendo que, entre os dias 19 de agosto de 2019 e 04 de novembro de 2019, ocorreu o plantio e o acompanhamento das espécies, totalizando 11 semanas de cultivo das amostras. No experimento 1 foram utilizados os contaminantes chumbo e níquel (obtidos por meio dos sais Acetato de Chumbo $\left(\mathrm{Pb}\left(\mathrm{C}_{2} \mathrm{H}_{3} \mathrm{O}_{2}\right)_{2}\right)$ e Sulfato de Níquel ( $\left.\mathrm{NiSO}_{4}\right)$ ambos com pureza entre 98 e 100\%) mesclados em uma mesma amostra, as concentrações para cada metal foram de 0,5, 1,0, 2,0 e 5,0 g/kg sendo a quantidade de solo seco igual a $2 \mathrm{~kg}$, foram plantadas sementes de mostarda e girassol. Para o experimento 2, foram plantadas sementes de Maricá em amostras contendo $1 \mathrm{~kg}$ de solo seco, contaminados somente com chumbo utilizando o mesmo sal do experimento 1 , as concentrações escolhidas foram de 0,25, 0,5 e 1,0 $\mathrm{g} / \mathrm{kg}$. Em ambos os experimentos foi utilizado amostragem em triplicatas sendo os resultados obtidos iguais às médias de cada tríplice. Observa-se também que o uso de somente um contaminante (chumbo) para o experimento 2 foi escolhido pois, como o Maricá não é considerado hiperacumulador pela literatura, a mistura de dois metais poderia atrapalhar o experimento e não gerar resultados satisfatórios. Para cada experimento foram estabelecidas triplicatas de amostras 'branco', ou seja, sem contaminantes.

\section{Metodologia USEPA 3050B}

Em relação às análises, fez-se uma adaptação da metodologia USEPA 3050B. Foi separado aproximadamente $10 \mathrm{~g}$ de cada amostra em béqueres de polipropileno (100 mL, J-Prolab), estas foram colocadas dentro de uma estufa de circulação de ar (Cienlab) para secagem por 24 horas à uma temperatura de $100 \pm 5$ ㄷ․ Após a secagem, as amostras foram maceradas com bastão de vidro e peneiradas em peneira de malha 100 (Mesh 100, Bertel), estas foram acondicionadas em recipientes com tampa de polipropileno.

As amostras foram digeridas em solução de ácido nítrico + ácido clorídrico. Para a realização do procedimento analítico, foram pesados $1 \mathrm{~g}$ de amostra em balança analítica (UW620H, Shimadzu), estas foram colocadas dentro em tubos de ensaio $(50 \times 250 \mathrm{~mm})$. Em cada tubo contendo amostra foi adicionado $10 \mathrm{~mL}$ de ácido nítrico $\left(\mathrm{HNO}_{3}\right)$ P.A. e colocados em bloco digestor (Tecnal) por 10 minutos em temperatura de $95 \pm 5$ 드, após este tempo os tubos foram resfriados em água até temperatura ambiente. Foi acrescentado mais $5 \mathrm{~mL}$ de e levados novamente para aquecer à $95 \pm 5$ ㅇ C por 2 horas, posteriormente estas foram resfriadas novamente. Acrescentou-se $2 \mathrm{~mL}$ de água deionizada $+3 \mathrm{~mL}$ de peróxido de hidrogênio $\left(\mathrm{H}_{2} \mathrm{O}_{2}\right) 35 \%$ 
Uso de Brassica Juncea (L.) Czern, Helianthus Annus L. e mimosa bimucronata (dc) o. Kuntze na fitorremediação de solos contaminados com

às amostras e estas foram digeridas por mais 2 horas no bloco à temperatura de $95 \pm 5 ㄷ$, após a digestão as amostras foram resfriadas novamente. Como última etapa da digestão adicionou-se $5 \mathrm{ml}$ de ácido clorídrico (HCl) P.A. $+10 \mathrm{~mL}$ de água deionizada aos tubos digerindo-os por mais 5 minutos à temperatura de $95 \pm 5$ 으. Após o procedimento de digestão, as amostras foram filtradas em papel filtro qualitativo (diâmetro $15 \mathrm{~cm}$, Unifil) e armazenadas em recipientes com tampa de polipropileno.

\section{Espectrofotômetro de Absorção Atômica por Chama - EAA}

As análises de concentrações foram feitas em Espectrofotômetro de Absorção Atômica por Chama EAA (NOVAA300, Analytik Jena). Para a obtenção da curva de calibração (Figuras 2 e 3) foram pesados 0,01 g dos sais utilizados para contaminação das amostras e cada porção de sal foi diluída em água deionizada em balão volumétrico de $1 \mathrm{~L}$ a fim de se conseguir solução mãe de $10 \mathrm{mg} / \mathrm{L}$, dilui- se a solução mãe para obter concentrações de $2,4,6$ e $8 \mathrm{mg} / \mathrm{L}$.

O comprimento de onda de absorção do chumbo foi de $283,3 \mathrm{~nm}$ e para o níquel utilizou-se o comprimento de $232,0 \mathrm{~nm}$, para ambas as curvas os valores para $\mathrm{R}^{2}$ se aproximaram de 1 (Tabela 1 ) o que demonstra que a estimativa de qualidade das curvas foi satisfatória uma vez que quanto mais próximo de 1 for o valor de $\mathrm{R}^{2}$, melhor será a reta descrita pela regressão linear dos pontos.

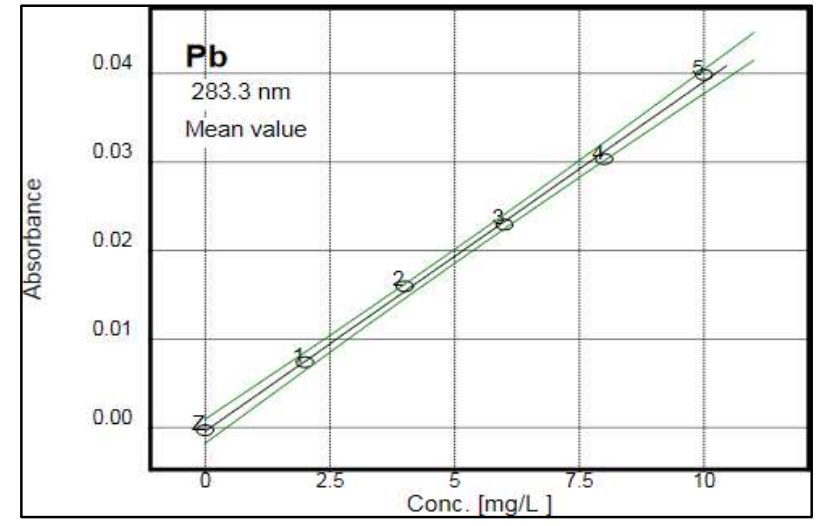

Figura 2: Curva de calibração para $\mathrm{Pb}$.

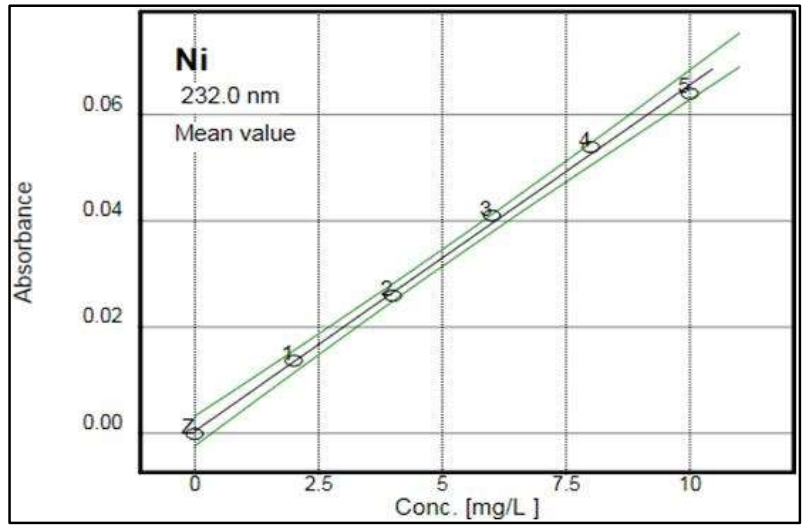

Figura 3: Curva de calibração para Ni.

Tabela 1: Valores para onda de absorbância $(\mathrm{nm})$ e $\mathrm{R}^{2}$ das curvas de calibração.

Valores para onda de absorbância $(\mathrm{nm})$ e $\mathbf{R}^{2}$ das curvas de calibração

\begin{tabular}{lll}
\hline Metal & Valor da onda $(\mathrm{nm})$ & ${\text { Valor de } \mathrm{R}^{2}}^{\text {Chumbo }}$ \\
Níquel & 283,3 & 0,9973 \\
\hline
\end{tabular}

Fez-se diluição de concentrações de $1 / 10$ para o chumbo e $1 / 200$ para o níquel. Para a primeira diluição, coletou-se $2,5 \mathrm{~mL}$ da amostra diluindo-a em água deionizada em balão volumétrico de $25 \mathrm{~mL}, \mathrm{para}$ a segunda diluição, selecionou-se 0,5 mL de amostra diluindo em balão volumétrico de $100 \mathrm{~mL}$.

\section{RESULTADOS E DISCUSSÃO}

Para a análise EAA as diluições foram necessárias para que as amostras não extrapolassem as curvas de calibração estabelecidas na metodologia. As amostras 'branco' não apresentaram valores significativos de 
Uso de Brassica Juncea (L.) Czern, Helianthus Annus L. e mimosa bimucronata (dc) o. Kuntze na fitorremediação de solos contaminados com

contaminação por chumbo ou níquel.

Para determinar o potencial fitoextrator das espécies estudadas, foi feito o cálculo da porcentagem fitorremediada em relação à concentração inicial de contaminante para o experimento 1 (Tabelas 2 e 3) e para o experimento 2 (Tabela 4), é importante lembrar que os valores dispostos nas Tabelas 2, 3 e 4 já estão multiplicados pelo valor de suas diluições.

É possível perceber que o experimento 1 obteve resultados mais satisfatórios de fitorremediação do que o experimento 2 considerando a porcentagem fitorremediada, isto ocorreu devido à maneira como foi feito o plantio das espécies. No experimento 1 as espécies foram plantadas juntas nas amostras então a porcentagem fitorremediada equivale à soma do potencial fitoextrator das duas espécies utilizadas (Girassol + Mostarda), o que impediu a determinação exata do potencial fitorremediador de cada espécie. Ambas as espécies são consideradas hiperacumuladoras de metais pela literatura, Boffe et al. (2017) em seu estudo atribui ao Girassol o título de planta hiperacumuladora de chumbo sendo que a espécie foi capaz de fitoextrair concentrações superiores a $900 \mathrm{mg} / \mathrm{kg}$ de chumbo. Em estudo realizado por Cruvinel (2009) observou-se que a Mostarda conseguiu fitorremediar 39, 38 e $29 \%$ de chumbo para amostras com concentrações de 180,360 e $540 \mathrm{mg} / \mathrm{kg}$ respectivamente.

Tabela 2: Porcentagens fitorremediadas e residuais das amostras para $\mathrm{Pb}$ no experimento 1.

\begin{tabular}{llll}
\hline Experimento $\mathbf{1}$ - Chumbo & & & \\
\hline Concentração Inicial (g/kg) & Concentração residual (g/kg) & \% de contaminante restante & \% fitorremediada \\
\hline $\mathbf{0 , 5}$ & 0,01921 & 3,8 & 96,2 \\
$\mathbf{1 , 0}$ & 0,09898 & 9,9 & 90,1 \\
$\mathbf{2 , 0}$ & 0,13133 & 6,6 & 93,4 \\
$\mathbf{5 , 0}$ & 0,24246 & 4,8 & 95,2 \\
\hline
\end{tabular}

Tabela 3 - Porcentagens fitorremediadas e residuais das amostras para Ni no experimento 1.

\begin{tabular}{llll}
\hline Experimento 1 - Níquel & & & \\
\hline Concentração Inicial (g/kg) & Concentração residual (g/kg) & \% de contaminante restante & \% fitorremediada \\
\hline $\mathbf{0 , 5}$ & 0,011 & 2,2 & 97,8 \\
$\mathbf{1 , 0}$ & 0,082 & 8,2 & 91,8 \\
$\mathbf{2 , 0}$ & 0,2602 & 13,0 & 87,0 \\
$\mathbf{5 , 0}$ & 0,6796 & 13,6 & 86,4 \\
\hline
\end{tabular}

Observou-se que no experimento 1 para chumbo, a taxa de fitorremediação das espécies não apresentou linearidade em relação à quantidade crescente de contaminantes nas amostras (Figura 4), o que sugere que a concentração de chumbo não foi obstáculo para o potencial fitorremediador das espécies. Para todas as concentrações, as espécies apresentaram potencial fitorremediador similar (>90\%) sendo que a média de variação entre as porcentagens fitorremediadas foi de 3,7\%. A dose de $1,0 \mathrm{~g} / \mathrm{kg}$ apresentou mais porcentagem de contaminante restante $(9,9 \%)$ e a dose de $0,5 \mathrm{~g} / \mathrm{kg}$ foi a amostra melhor fitorremediada restando $3,8 \%$ de chumbo.

Em relação ao níquel, a porcentagem de fitorremediação apresentou característica linear considerando o aumento de contaminantes no solo (Figura 4), sugerindo que o Girassol e a Mostarda apresentam dificuldades em fitoextrair níquel em concentrações elevadas no solo. A dose de 0,5 g/ $\mathrm{kg}$ foi a amostra melhor fitorremediada restando $2,2 \%$ de níquel, já na dose $5,0 \mathrm{~g} / \mathrm{kg}$ as espécies apresentaram 
Uso de Brassica Juncea (L.) Czern, Helianthus Annus L. e mimosa bimucronata (dc) o. Kuntze na fitorremediação de solos contaminados com

maiores dificuldades de fitoextrair níquel do solo em relação as demais concentrações resultando em 13,6\% de contaminante não fitorremediado.

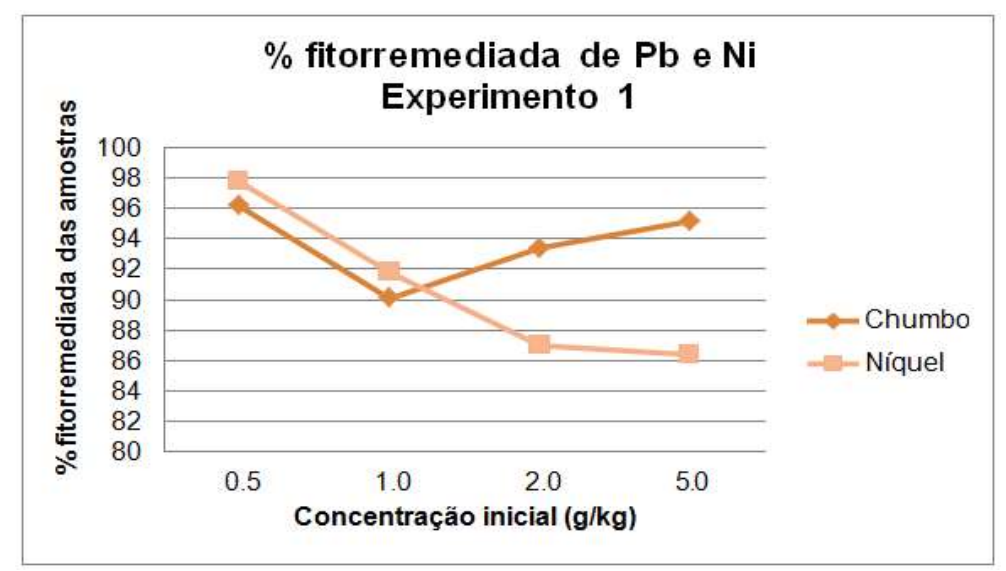

Figura 4: Porcentagem total fitorremediada de $\mathrm{Pb}$ e Ni para o experimento 1.

Para a primeira concentração as espécies apresentaram ótimo potencial fitoextrator de chumbo e níquel conseguindo retirar acima de 96,2 e 97,8\% respectivamente dos contaminantes das amostras e para a segunda concentração as espécies conseguiram extrair $90,1 \%$ de chumbo e $91,8 \%$ de níquel. Verifica-se que para as concentrações mais baixas o Girassol e a Mostarda apresentam maior absorção de níquel do que de chumbo.

Na concentração de $2,0 \mathrm{~g} / \mathrm{kg}$ foi fitoextraído $93,4 \%$ de chumbo e $87,0 \%$ de níquel e para a última concentração, as espécies conseguiram fitorremediar $95,2 \%$ de chumbo e $86,4 \%$ de níquel. É importante observar que para os resultados do experimento 1, a mistura dos contaminantes e o cultivo de duas espécies de plantas em uma mesma amostra podem ter causado interferências devido à concorrência fitoextratora das espécies e afinidade destas para extrair um contaminante ou outro.

No segundo experimento, o Maricá obteve mais sucesso em fitorremediar a amostra contendo menor concentração de contaminante fitoextraindo 55,3\% de chumbo. Para as concentrações de 0,5 e 1,0 $\mathrm{g} / \mathrm{kg}$ o potencial fitoextrator foi de 38,3 e $37,7 \%$ respectivamente (Tabela 4 ).

Tabela 4: Porcentagens fitorremediadas e residuais das amostras para Pb no experimento 2 (Autor, 2019).

\begin{tabular}{llll}
\hline Experimento 2 - Chumbo & & & \\
\hline Concentração Inicial (g/kg) & Concentração residual (g/kg) & \% de contaminante restante & \% fitorremediada \\
\hline $\mathbf{0 , 2 5}$ & 0,11184 & 44,7 & 55,3 \\
$\mathbf{0 , 5}$ & 0,3085 & 61,7 & 38,3 \\
$\mathbf{1 , 0}$ & 0,62297 & 62,3 & 37,7 \\
\hline
\end{tabular}

Percebe-se pela Figura 5 que, conforme a concentração de chumbo aumentou, a espécie apresentou menores taxas de fitoextração. Para menor concentração o Maricá conseguiu retirar 55,3\% de contaminante do solo, para a concentração de $0,5 \mathrm{~g} / \mathrm{kg}$ foi fitorremediado $38,3 \%$ sendo que para a concentração de 1,0 $\mathrm{g} / \mathrm{kg}$, a porcentagem fitorremediada $(37,7 \%)$ ficou bem próxima da porcentagem da concentração anterior.

Comparando-se os resultados dos dois experimentos, é possível analisar que o Maricá apresentou potencial fitorremediador considerando que este foi capaz de fitorremediar sozinho 38,3 e $37,7 \%$ para as concentrações de 0,5 e 1,0 g/kg respectivamente sendo que para as mesmas concentrações, o Girassol e a 
Uso de Brassica Juncea (L.) Czern, Helianthus Annus L. e mimosa bimucronata (dc) o. Kuntze na fitorremediação de solos contaminados com

Mostarda juntos fitorremediaram 96,2 e 90,1\% de chumbo respectivamente (Figura 6).

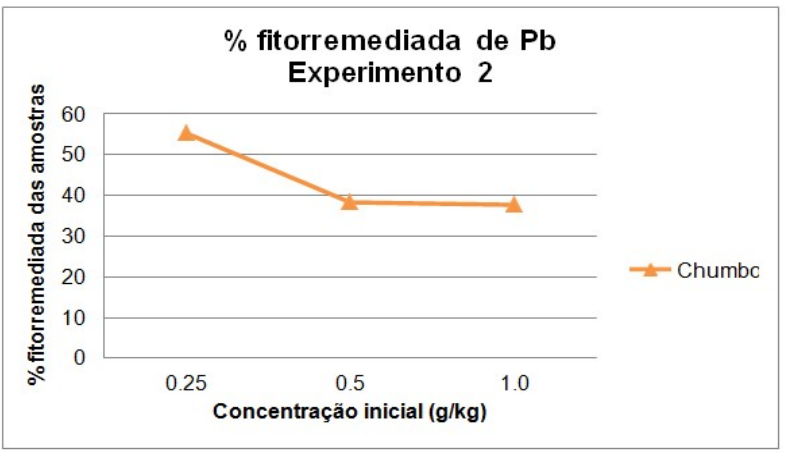

Figura 5: Porcentagem total fitorremediada de $\mathrm{Pb}$ para o experimento 2 .

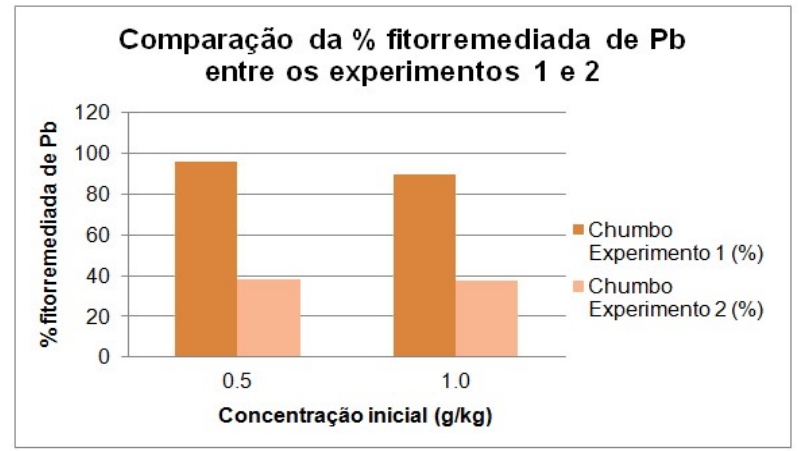

Figura 6: Comparação da \% fitorremediada de $\mathrm{Pb}$ entre os experimentos 1 e 2.

O potencial fitorremediador do Maricá aproximou-se da metade do potencial fitorremediador Girassol + Mostarda o que demonstra que, mesmo não sendo uma espécie considerada hiperacumuladora pela literatura, a espécie apresentou bons resultados de fitoextração.

Deve-se considerar para este estudo que não foi feito a medição de parâmetros físicos das espécies como tamanho radicular, contagem de folhas, presença de manchas no indivíduo entre outros uma vez que a metodologia utilizada foi elaborada com ênfase na digestão do solo das amostras como alternativa aos procedimentos usuais de digestão do tecido vegetal.

\section{CONCLUSÕES}

As três espécies estudadas apresentaram resultados satisfatórios em relação à fitoextração de chumbo e níquel sendo que Girassol e Mostarda juntos conseguiram remediar acima de $90 \%$ o chumbo e acima de $85 \%$ o níquel. O Maricá sozinho fitorremediou até $55 \%$ o chumbo das amostras o que demonstra que a espécie possui potencial para fitorremediação mesmo não sendo considerada uma planta hiperacumuladora de metais. Considerando o chumbo, Girassol e Mostarda não apresentaram problemas em extrair contaminante de amostras com concentrações mais elevadas, fato que não condiz com o níquel onde foi observado um decaimento do potencial fitorremediador conforme a concentração de níquel aumentava. O Maricá demonstrou dificuldade em extrair metais nas concentrações mais elevadas (0,5 e 1,0 $\mathrm{g} / \mathrm{kg}$ ) sendo que a porcentagem extraída se manteve próxima para estas concentrações (38,3 e 37,7\% respectivamente).

Em relação ao Maricá, há poucos estudos sobre o potencial fitoextrator da espécie fato que merece atenção, pois a planta conseguiu fitorremediar porcentagens significativas de chumbo se considerar que não é uma espécie adaptada para fitorremediação. Com estudos mais aprofundados seria possível determinar se a espécie consegue extrair outros tipos de metais como Níquel, Cádmio, Zinco, Cobre, Cobalto etc. Além de verificar o efeito destes contaminantes nos indicadores físicos da planta.

Foi possível verificar que o uso de Mostarda e Girassol para fitorremediar uma mesma amostra foi mais efetiva do que o uso de apenas Maricá, este dado deve ser mais estudado, pois o uso de diferentes indivíduos pode gerar conflito nos resultados uma vez que pode ter ocorrido concorrência fitoextratora entre 
as espécies e não foi verificado a afinidade destas para extrair cada contaminante. É importante considerar que também não foi verificado o potencial separado do Girassol e da Mostarda. Para que se tenham resultados mais abrangentes seria necessário testar o potencial do Girassol e da Mostarda separados e a combinação de diferentes espécies.

Apesar dos resultados satisfatórios, analisar os parâmetros físicos das plantas seria um procedimento que contribuiria com os resultados deixando-os mais completos, possibilitando uma visão mais abrangente do real potencial das espécies estudadas e os efeitos dos metais em seus processos de crescimento.

\section{REFERÊNCIAS}

AGEITEC. Agência Embrapa de Informação Tecnológica. Latossolos vermelhos. AGEITEC, 2019.

ANDRADE, J. C. M.; TAVARES, S. R. L.; MAHLER, C. F.. Fitorremediação: o uso de plantas a melhoria da qualidade ambiental. São Paulo: Oficina de Textos. 2007.

BAKER, A. J. M.; MCGRATH, S. P.; SIDOLI, C. M. D.; REEVES, R. D.. The possibility of in situ heavy metal decontamination of polluted soils using crops of metal-accumulating plants. Resources, Conservation and Recycling, v.11, n.1-4, p.41-49, 1994. DOI: https://doi.org/10.1016/0921-3449(94)90077-9

BOFFE, P. M.; CALEGARI, R. P.; SOUZA, D. C. R.; CONCEIÇÃO, P. S.; SZYMCZAK, D. A.; TESSARO, D.. Potencial fitoextrator da espécie vegetal Helianthus annus L. em solo contaminado por chumbo. Revista Espacios, v.39, n.09, p.8, 2017.

CRUVINEL, D. F. C.. Avaliação da fitorremediação em solos submetidos à contaminação com metais. Dissertação (Mestrado em Tecnologia Ambiental) - Centro de Ciências Exatas, Naturais e Tecnologias. Universidade de Ribeirão Preto. Ribeirão Preto, 2009.

DAS, K. K.; REDDY, C.; BAGOJI, I. B.; DAS, S.; BAGALI, S.; MULLUR, L.; KHODNAPUR, J. P.; BIRADAR, M. S.. Primary concept of nickel toxicity: an overview. Journal of Basic and Clinical Physiology and Pharmacology, v.30, n.2, p.141-152, 2018.

DINIZ, A. P.; KOZIVITS, A. R.; LANA, C. C.; LEITE, M. G. P.. Fitoextração de metais de espécies florestais nativas plantadas sobre rejeito de mineração de ferro. Dissertação (Mestrado em Evolução Crustal e Recursos Naturais) Universidade Federal de Ouro Preto, Ouro Preto, 2018.

EMBRAPA. Empresa Brasileira de Pesquisa Agropecuária. Manual de métodos de análise do solo. Centro Nacional de Pesquisa de Solos. 2 ed. 1997.

ESTRELA, M. A.; CHAVES, L. H. G.; SILVA, L. N.. Fitorremediação como solução para solos contaminados por metais pesados. Ceuma Perspectivas, v.18, p.160-172, 2018.

FABRO, N.. Moradores de Brumadinho correm riscos de desenvolver doenças cardiovasculares. Revista Galileu, São Paulo, 2019.

FREITAS, C. M.; BARCELLOS, C.; ASMUS, C. I. R.; SILVA, M. A.; XAVIER, D. R.. Samarco em Mariana à Vale em Brumadinho: desastres em barragens de mineração e Saúde Coletiva. Cadernos de Saúde Pública. Mineração e desastres ambientais. Rio de Janeiro, 2019.

GREIPSSON, S.. Phytoremediation. Nature Education Knowledge, v.3, n.10, p.7, 2011.

GUARACHO, V. V.; PONTE, M. J. J. S.; ADAMOSKI, L. F.. Remediação eletrocinética de chumbo e níquel em solos de landfarming de uma refinaria. In: CONGRESSO BRASILEIRO DE CIÊNCIA E TECNOLOGIA EM RESÍDUOS E DESENVOLVIMENTO SUSTENTÁVEL. Anais. Florianópolis: Instituto de Ciência e Tecnologia em Resíduos e Desenvolvimento Sustentável, 2004.

MARTINEZ, M. S.; CRUVINEL, D. F. C.; BARATTO, D. M.. Avaliação da fitorremediação de solos contaminados com metais pelo capim braquiária e mostarda da Índia. Revista DAE, v.61, n.191, p.30-37, 2013.

MONTEIRO, M. T.. Fitorremediação de rejeito contaminado proveniente do Canal do Fundão, na Baía da Guanabara-RJ. Tese (Doutorado em Engenharia Civil) - Universidade Federal do Rio de Janeiro, Rio de Janeiro, 2005.

MOTA, C. V.. Exames constatam intoxicação por metais pesados em moradores de cidade atingida pelo desastre de Mariana. São Paulo: BBC Brasil, 2018.

MULLIGAN, C. N.; YONG, R. N.; GIBBS, B. F.. Remediation Technologies for metalcontaminated soils and groundwater: an evaluation. Engineering Geology, v.60, p.193-207, 2001.

RIBEIRO, L.; CRUZ, M. M.. Saiba quais são as impurezas da lama da barragem de Brumadinho e os riscos à saúde. Belo Horizonte, 2019.

SILVA, T. J.. Fitorremediação em escala piloto: proposta para recuperação de solos contaminados com cobre e zinco. Dissertação (Mestrado em Ciências Ambientais) Universidade Estadual Paulista Júlio de Mesquita Filho, Sorocaba, 2016.

UNEP. United Nations Environment Programme.

Phytoremediation: an environmentally sound technology for pollution prevention, control and redmediation. Newsletter and Technical Publications, Freshwater Management Serie. UNEP, 2018. 
Uso de Brassica Juncea (L.) Czern, Helianthus Annus L. e mimosa bimucronata (dc) o. Kuntze na fitorremediação de solos contaminados com chumbo e níquel

TOKUHO, M. Y.; CONSOLIN FILHO, N.; MEDEIROS, F. V. S.; ARAÚJO, J. H. B.

USEPA. United States Environmental Protection Agency. Method 3050B: Acid Digestion of Sediments, Sludges, and Soils. EPA/3050B-SW-846. USEPA, 1996.

ZHOURI, A.; OLIVEIRA, R.; ZUCARELLI, M.; VASCONCELOS, M.; LOSEKANN, C.; SANTOS, R. S. P.; MILANEZ, B.; ACSELRAD,
H.. Dossier 'Mining, violence and resistance'. Part 1: The Samarco mining disaster: affectations, resistance, policies. Vibrant. Associação Brasileira de Antropologia, Brasília, v.14, n.2, p.81-183, 2017.

A CBPC - Companhia Brasileira de Produção Científica (CNPJ: 11.221.422/0001-03) detém os direitos materiais desta publicação. Os direitos referem-se à publicação do trabalho em qualquer parte do mundo, incluindo os direitos às renovações, expansões e disseminações da contribuição, bem como outros direitos subsidiários. Todos os trabalhos publicados eletronicamente poderão posteriormente ser publicados em coletâneas impressas sob coordenação da Sustenere Publishing, da Companhia Brasileira de Produção Científica e seus parceiros autorizados. Os (as) autores (as) preservam os direitos autorais, mas não têm permissão para a publicação da contribuição em outro meio, impresso ou digital, em português ou em tradução. 